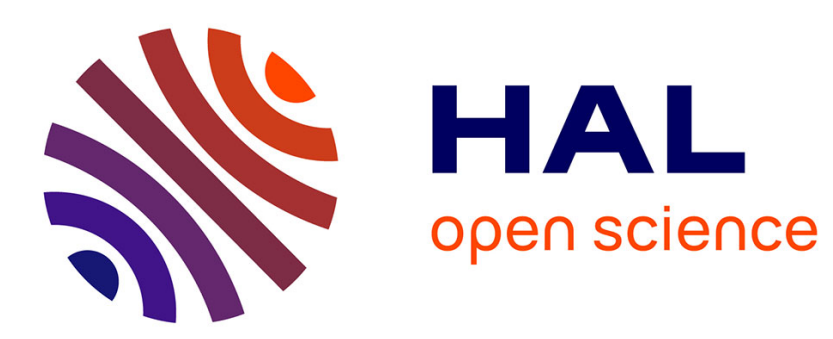

\title{
Volumetric changes in weathered profiles: iso-element mass balance method questioned by magnetic fabric
}

\author{
P.-E. Mathe, Pierre Rochette, Didier Vandamme, Fabrice Colin
}

\section{To cite this version:}

P.-E. Mathe, Pierre Rochette, Didier Vandamme, Fabrice Colin. Volumetric changes in weathered profiles: iso-element mass balance method questioned by magnetic fabric. Earth and Planetary Science Letters, 1999, 167 (3-4), pp.255-267. 10.1016/S0012-821X(99)00024-2 . hal-03562965

\section{HAL Id: hal-03562965 \\ https://hal.science/hal-03562965}

Submitted on 9 Feb 2022

HAL is a multi-disciplinary open access archive for the deposit and dissemination of scientific research documents, whether they are published or not. The documents may come from teaching and research institutions in France or abroad, or from public or private research centers.
L'archive ouverte pluridisciplinaire HAL, est destinée au dépôt et à la diffusion de documents scientifiques de niveau recherche, publiés ou non, émanant des établissements d'enseignement et de recherche français ou étrangers, des laboratoires publics ou privés. 


\title{
Volumetric changes in weathered profiles: iso-element mass balance method questioned by magnetic fabric
}

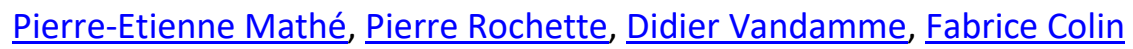

Abstract

A major issue in understanding weathering processes is to determine to what extent fabrics, structures and volumes from the parent rock are preserved through the weathering profile. Isoelement mass balance methods (IMB) are often used to estimate volume changes during progressive weathering, based on the assumption that a given element (either $\mathrm{Ti}, \mathrm{Zr}$ or $\mathrm{Th}$ ) is not mobile. The petrofabric of the weathered material is often characterized by a mimetic replacement of primary minerals that fully preserve the primary fabric. This suggests an isovolume weathering as volume change must be associated with shape change due to boundary conditions not allowing horizontal strains. So collapse or dilation should induce vertical compaction or constriction, respectively. The weak petrofabric of weathered materials may be precisely quantified using the anisotropy of low-field magnetic susceptibility technique (AMS). This paper reports, for the first time, a combined IMB and AMS study of two different environments: a complex lateritic sequence on Precambrian metamorphic rocks in Cameroon and a weathering profile on a Pleistocene basaltic flow in Morocco. The lateritic profile, divided into a lower saprolite zone $(>12 \mathrm{~m})$ and an upper nodular iron-rich unit $(4 \mathrm{~m})$, is characterized by neoformed magnetic minerals (goethite/hematite/spinels) and a weak but rather consistent magnetic fabric. Saprolitization, which induces low susceptibility values $\left(50 \times 10^{-9} \mathrm{~m}^{3} / \mathrm{kg}\right)$, preserves the linear tectonic fabric of the parent gneiss. AMS evidence for isovolumetric weathering agrees with $\mathrm{Th}$ based IMB, while Ti and $\mathrm{Zr}$ partly indicate apparent collapse and dilation (up to 50\%), respectively. Ferralitization in the nodular iron crust, which enhances susceptibilities (500 to $700 \times 10^{-9} \mathrm{~m}^{3} / \mathrm{kg}$, due to spinel phases), induces drastic reductions in anisotropy due to multiple generation of neoformed minerals destroying primary fabric. However, a weak horizontal planar magnetic fabric suggests compaction, in agreement with Th and Ti based IMB while $\mathrm{Zr}$ would indicate isovolume weathering. Conversely, in the one meter thick weathering profile on basalt, the strong susceptibility $\left(1.5\right.$ to $\left.3 \times 10^{-6} \mathrm{~m}^{3} / \mathrm{kg}\right)$ is dominated by inherited titanomaghemite grains which totally preserve the weak magmatic fabric of the fresh basalt. This again suggests that volume change is minor, while $\mathrm{Ti}$ and $\mathrm{Zr}$ based IMB indicate 20 to $50 \%$ of dilation. In both examples, large volume changes inferred from the IMB in units showing preserved primary AMS fabric appear unrealistic. Our AMS study, together with the large discrepancies between the IMB results produced by various elements, indicate that the assumption of immobility of a given element is probably not fulfilled all along these profiles. Isovolumetric weathering in the saprolitic zone may be more widespread than suggested by IMB

\section{Keywords}

Laterites, weathering, basalts, anisotropy, magnetic susceptibility, mass balance 


\section{Introduction}

Recent models consider soils and weathering mantles as a geomenbrane sensitive to climatic changes through chemical and physical transfers [1]. To quantify such geochemical transfers in an attempt to model the contributions of past climatic changes to the dynamics of weathering and soil evolution, the iso-element mass balance methods (IMB) are widely used.

The IMB methods, e.g. iso-niobium $\underline{2}, \underline{3}$, iso-titanium $\underline{4}, \underline{5}$, iso-thorium $\underline{2}$, $\underline{6}$ or iso-zirconium $\underline{7}$, $\underline{8}$, assume that some element remains immobile during weathering processes (see $\underline{\text { Section }}$ 2.1for details). Since the validity of such mass transfers quantification strongly depends of the geochemical behavior of the element chosen as reference for calculation, several of these methods are usually applied to minimize bias due to the possible mobility of a single element. However, this does not always ensure the validity of results, as the relevance of the preferred methods may in turn depend on the observation scales, from landscape to crystal scale $\underline{9}, \underline{10}$. The IMB methods can be used to test the validity of the model of isovolumetric weathering [11]. This model is based on the observation of conservative structures, at the macroscopic (e.g. quartz veins and tectonic structures) and microscopic (mineral preferred orientation or petrofabric) scales [10]. Indeed, a volume change cannot correspond to an isotropic strain in a natural weathering profile as the material is free to expand or contract only along the vertical dimension (i.e. perpendicular to the surface). Therefore, in a simple homogeneous vertical gradient of weathering, from the underlying parent fresh rock to the topsoil, a volume decrease (collapse) must correspond to a compaction (flattening) and a volume increase (dilation) must correspond to a vertical constriction (stretching), both inducing a modification of petrofabric. Although more complex situations, involving heterogeneous weathering (such as ball formation) or along slope extension (due to downslope creep), can be encountered, there is no way to imagine a situation where strain would be isotropic in case of volume changes, that is the relative length variation of the material would be equal in every horizontal and vertical directions.

The anisotropy of magnetic susceptibility (AMS) is a well established and versatile technique $\underline{12}, \underline{13}$ allowing one to quantify, with a high sensitivity, the preferred orientation of magnetic minerals (i.e. the magnetic fabric). The aim of the present study is therefore to test the use of AMS in two contrasted weathering profiles from Cameroon and Morocco to check the validity of IMB results. Bulk magnetic properties of weathered materials have been reported by various authors $\underline{14}, \underline{15}, \underline{16}, \underline{17}, \underline{18}$, mostly in soils rather than continuous profiles [18]. Paleomagnetic investigations $\underline{19}, \underline{20}, \underline{21}$ of weathering profiles have also been undertaken, in particular to define the age of lateritization. However, no AMS study has been devoted so far to weathering profiles.

\section{Sampling and methods}

\subsection{Sampling}

Oriented blocks or core regularly distributed on vertical profiles were sampled from three along slope pits in Cameroon and a roadcut in Morocco. Soft material was carved in large plastic boxes while stronger material (in Morocco) was cored with a portable drill, producing cylinders $25 \mathrm{~cm}$ in diameter. The bulk material was used to measure the porosity and AMS. For the softer material an epoxy resin was first injected in the large blocks before cutting small size cubes readily measurable for AMS. Geochemical analysis were performed on the same powdered samples. 
Fresh parent rock was obtained at the base of the profile in Morocco, while the Cameroon pits do not reach the fresh rock, which was obtained from river boulders.

\subsection{Iso-element mass balance (IMB)}

Formal mass-balance equations are based on weathered material chemical composition and physical properties such as bulk density, grain density and porosity, and the corresponding properties of the parent rock. Assuming the immobility of some trace elements during geochemical weathering, mass transfers of the other elements (gains or losses) and volumetric changes of rocks (strain, i.e. collapse or dilation) are calculated, with respect to the index element taken as reference, from the following equations [7]. Porosity $(\varphi)$ is defined by:(1)

where $\rho_{\mathrm{d}}$ is the bulk density and $\rho_{\mathrm{g}}$ the grain density.

Volumetric change (or strain $\varepsilon_{i}$ ) is defined by:(2)

where $\rho$ is the bulk density, w and p subscripts refer to weathered and parent rock respectively); $i$ pertains to the index element taken as reference and $C$ its concentration in weight $\%$. Negative or positive values of strain indicate collapse or dilation, respectively.

To estimate possible bias due to the mobility of a single index element, calculations were conducted using titanium, zirconium and thorium, which are the most extensively used among the potential immobile elements.

Rock powders were used to perform chemical analyses of major elements (given in weight $\%$ oxides) such as $\mathrm{TiO}_{2}$ (detection limit at $5 \mathrm{ppm}$ ) and trace elements: $\mathrm{Zr}(2 \mathrm{ppm})$, Th (2 ppm) with Inductively Coupled Plasma Spectrometer (ICP-OES).

\subsection{Anisotropy of magnetic susceptibility (AMS)}

At the grain scale, AMS is controlled by crystallographic system, iron oxidation state and crystal sites. Grain shape may also play a role in minerals of high susceptibility such as spinel [12]. At the macroscopic scale, AMS arises from the preferred orientation of anisotropic magnetic minerals, the so-called magnetic fabric. It generally corresponds to the petrofabric itself, but may be complicated by specific rock magnetic effects, reviewed by Rochette et al. [12]. The assessment of geological significance of AMS data in terms of petrofabric requires thus careful control, and therefore, in the two following examples, the AMS study was undertaken together with rock magnetic, mineralogical, structural and geochemical investigations.

The output of AMS measurements is an ellipsoid defined by the length and the orientation of its three principal susceptibility axes $K_{1} \geq K_{2} \geq K_{3}$, i.e. the three eigen-vectors of the susceptibility tensor. The widely used parameters that control the magnitude and shape of the AMS ellipsoid [13] are defined as follow: the mean magnetic susceptibility $K_{\mathrm{m}}=\left(K_{1}+K_{2}+K_{3}\right) / 3$, expressed here as specific values $\chi_{\mathrm{m}}$ (in $10^{-9} \mathrm{~m}^{3} / \mathrm{kg}$ ); $P=K_{1} / K_{3}$, the anisotropy degree; $L=K_{1} / K_{2}$, the magnetic lineation; $F=K_{2} / K_{3}$, the magnetic foliation and $T=\left[2\left(\ln K_{2}-\ln K_{3}\right) /\left(\ln K_{1}-\ln K_{3}\right)\right]-1$, the shape parameter, which characterizes the shape of the AMS ellipsoid ( $T=1$ for pure oblateness whereas $T=-1$ for pure prolateness). Results reported here are mean tensorial values obtained on at least 3 samples in each layer collected, following Jelinek [22]. 
Measurements were performed at room temperature on $8 \mathrm{~cm}^{3}$ cubic plastic boxes or standard cylindrical core samples, on a Kappabridge KLY-2 a.c. bridge, which allows the determination of $P$ and $\chi_{\mathrm{m}}$ with sensitivities up to 1.002 and $10^{-9} \mathrm{~m}^{3} / \mathrm{kg}$, respectively.

\section{The Goyoum profile (Cameroon)}

A lateritic nodular soil sequence located near Goyoum (Cameroon) at $4^{\circ} 95^{\prime} \mathrm{N}$ has been the subject of a complete structural and petrogeochemical spatial analysis [23]. In this area, deep pedological mantles have evolved by long-term weathering of gneissic rocks of the basal Precambrian complex under a tropical humid environment, leading to characteristic landscape morphology of 'half-orange' hills. For our magnetic study vertical sections from three pits distributed along a hill slope have been investigated [24]. Results from only the hilltop $12 \mathrm{~m}$ section (pit 352) is reported here because this section exhibit the most complete sequence and pronounced contrasts. Its hilltop situation (i.e. on a flat surface) also excludes downhill creep.

\subsection{Petrological and mineralogical patterns}

The typical textural organization of the profile consists mainly in four units (Fig. 1, Table 1). At the bottom lies (I) a coarse saprolitic unit (C-horizon), evolving through (II') a structural transition (BC-horizon) in its upper part, to (II) a red nodular one (B-horizon). The upper unit (III) is a soil (A-horizon), with a thin superficial organic matter-rich unit (A0, Mor). The main petrological features were investigated in details by X-ray diffraction (XRD), Transmission Electron Microscope (TEM), Scanning Electron Microscope (SEM) and optical microscope [23](see synthesis in Table 1). Kaolinite, Al-substituted hematite and goethite represent the major weathering products. Quartz, biotite and muscovite are the main primary residual minerals.

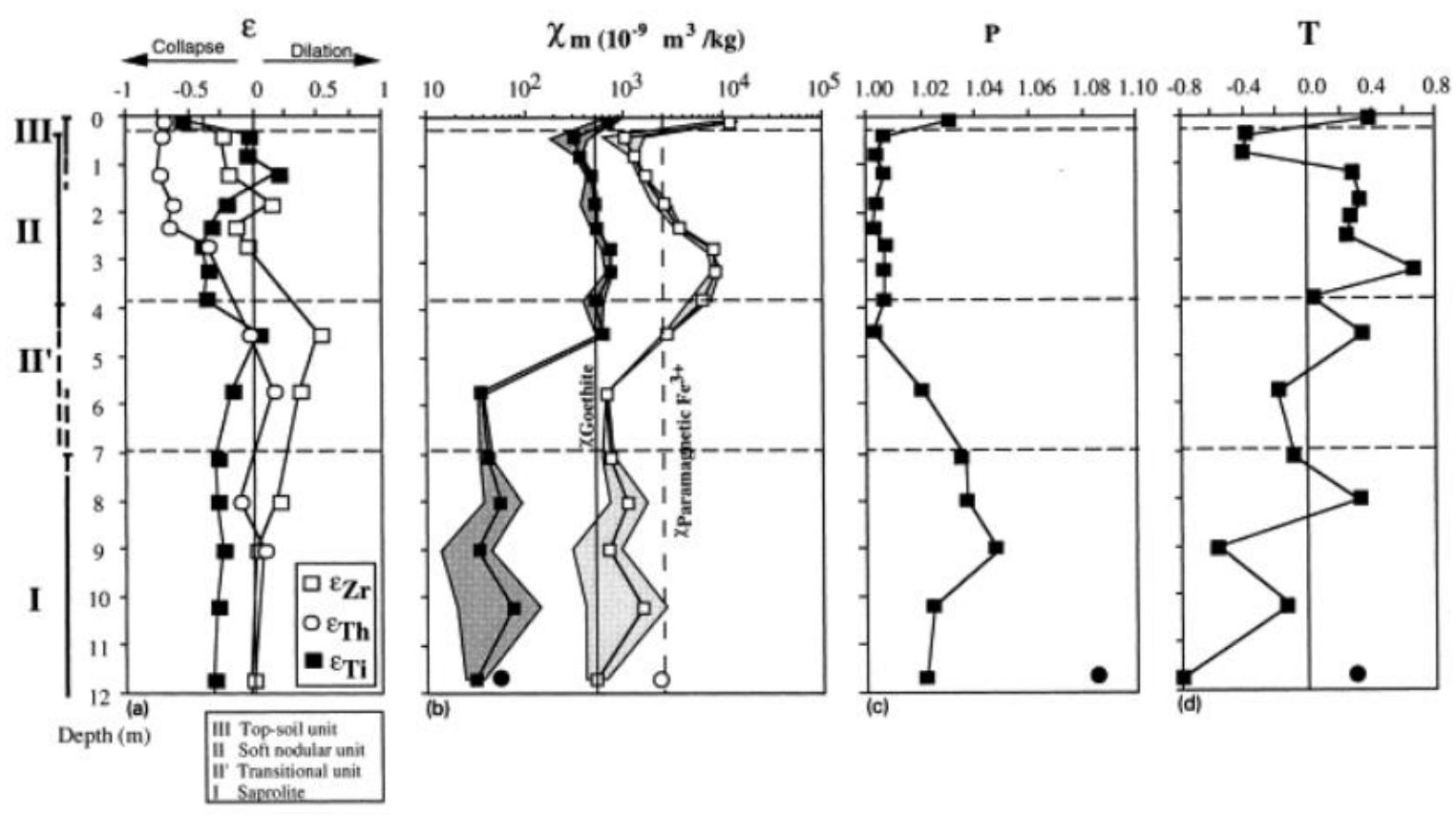

Fig. 1. Volumic IMB strain and AMS parameters of the Goyoum profile 352 as a function of depth. (a) Strain $\varepsilon$ using calculated zirconium, titanium and thorium as index element $i$. (b) Mean susceptibility $\chi_{\mathrm{m}}$ (in $10^{-9} \mathrm{~m}^{3} / \mathrm{kg}$ ) (solid square or dot for the parent rock) and mean 
susceptibility normalized to iron content (expressed as Fe) (open square or circle for the parent rock); (shaded zones indicate maximum and minimum susceptibilities for each sampled layer); reference values normalized to Fe are shown for goethite and paramagnetic $\mathrm{Fe}^{3+}$. (c, d) Tensorial mean values of anisotropy degree $P$ and shape parameter $T$; dot for subfresh gneissic samples.

Table 1. Morphological and mineralogical features of the Goyoum profile (after Muller, 1987) [25]

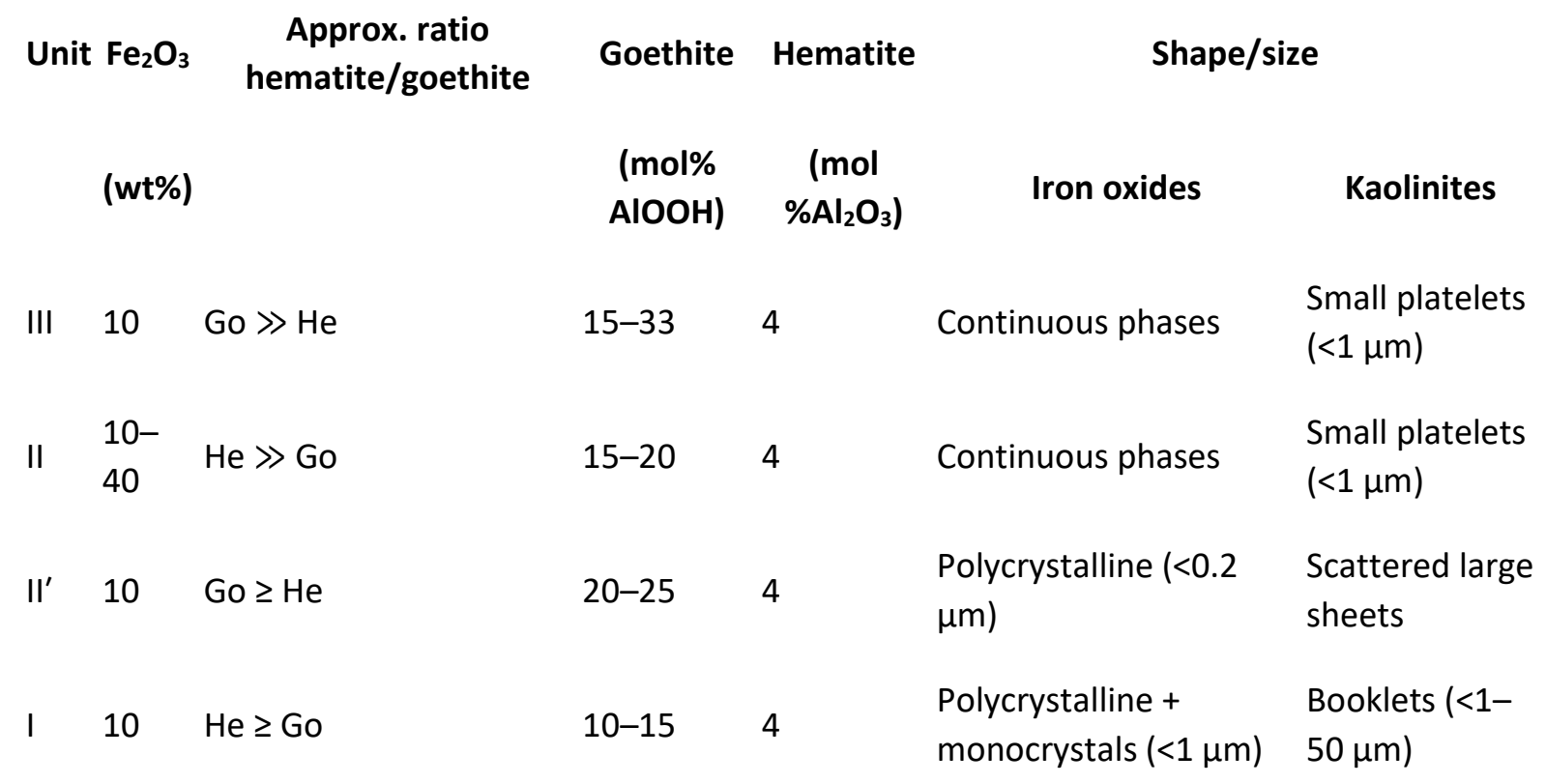

In the saprolitic unit, the initial foliation is preserved, underlined by the preferred orientation of primary muscovite and kaolinite platelets that have pseudomorphically replaced biotite and feldspar. Iron oxides generally form coatings around kaolinite particles. The structural transition show local anisotropy related to exfoliated kaolinite booklets from residual muscovite. The nodular unit exhibits ferruginous nodules within clayey matrix of small kaolinite platelets, polycrystalline grains of goethite, hematite and quartz grains, without any visible preferred orientation, showing an apparent complete homogenization due to ferralitic processes. The topsoil unit shows a granular texture of very fine-grained clay material.

\subsection{Volume changes from IMB}

Porosity appears quite constant at about $50 \%$ in zone I and II', while it decreases regularly upward in the nodular and topsoil units (down to 25\%). Strain calculations were carried out here using $\mathrm{Th}, \mathrm{Ti}, \mathrm{Zr}$ as index element (i) in Eq. (2), no matter whether they appear in individual weathering resistant minerals or not. The initial concentration of elements used as a reference for parent rock were calculated from mean value for five gneissic samples collected in boulders located at the bottom of the toposequence, since it is the only place where the (sub)-fresh parent rock outcrops.

The results show considerable differences depending on the chosen element (Fig. 1a). Assuming the initial homogeneity of the parent rock in terms of index element content, the nearly constant trends through the saprolitic unit testify for minor volumetric changes, whatever the index element. However, $\varepsilon_{\mathrm{Ti}}$ indicates about $25 \%$ collapse while $\varepsilon_{\mathrm{Th}}$ and $\varepsilon_{\mathrm{Zr}}$ point 
toward isovolumetric saprolitization $\left(\varepsilon_{i}=0\right)$. This contrasting behavior may arise either from the relative mobility of titanium versus thorium and zirconium or from a lower titanium content of the true parent rock compared to the mean value calculated from our samples. On the other hand the transition zone shows approximately no volume change according to Ti and Th, while $\varepsilon \mathrm{Zr}$ reaches up to $50 \%$ dilation. In the nodular unit, as well as in the topsoil unit, calculations indicate that collapse, up to $60 \%$ as found elsewhere $\underline{25}, \underline{26}$, is predominant, although $\mathrm{Zr}$ and $\mathrm{Ti}$ indicate isovolume zones. This collapse is in agreement with the observed porosity reduction.

Even though the strain values might be incorrect, due to the heterogeneity of gneissic samples chosen as reference, this cannot explain the difference observed in the upper horizons. Hence, it clearly points toward the differential geochemical behavior of the index elements during ferralitization. Probably neither $\mathrm{Ti}$, Th or $\mathrm{Zr}$ are immobile throughout the whole profile.

\subsection{Magnetic results}

\subsubsection{Low-field susceptibility profiles}

Mean magnetic susceptibility $\left(\chi_{\mathrm{m}}\right)$ profiles allow the discrimination of the different units (Fig. $\underline{1 b}$ ), despite the mineralogical heterogeneity of the layers sampled, which give more or less narrow susceptibility ranges (indicated by the shaded zone).

In the parent rock, saprolitic (I) and transitional (II') units, low $\chi_{\mathrm{m}}$ values $\left(<100 \times 10^{-9} \mathrm{~m}^{3} / \mathrm{kg}\right)$ indicate antiferromagnetic (hematite and Al-poor goethite) and paramagnetic contributions, the latter involving primary phyllosilicates, Al-rich goethites and amorphous iron phases 24 , 27. According to high field measurements [24]the contribution of primary or neoformed ferrimagnetic spinels is negligible. Once normalized to iron amount, observed susceptibility values $\left(\chi_{\mathrm{mFe}}\right)$ can be compared to the reference values for goethite and paramagnetic $\mathrm{Fe}^{3+} \underline{12}$, $\underline{24}$, showing that a mixing of these two contributions can explain the results (Fig. 1b).

However, the similarity between $\chi_{\mathrm{mFe}}$ and $\chi_{\mathrm{m}}$ suggests that the observed fluctuations in $\chi_{\mathrm{m}}$ are due to slight variations in the iron content rather than changes of the iron magnetic state, reflecting the initial heterogeneity of the parent rock.

In the nodular unit (II), $\chi_{\mathrm{m}}$ values up to more than $700 \times 10^{-9} \mathrm{~m}^{3} / \mathrm{kg}$ cannot be solely attributed to minerals of low susceptibility such as hematite and goethite $\left(\chi_{\mathrm{m}}<500 \times 10^{-9} \mathrm{~m}^{3} / \mathrm{kg} \underline{28}, \underline{29}\right)$, while large variations of $\chi_{\mathrm{mFe}}$ imply changes in the iron magnetic state. Therefore, traces of a ferrimagnetic phase such as maghemite are necessary to explain the magnetic properties, as it was already suggested in a previous TEM study [30]. The top soil unit (III) exhibits a drastic increase in $\chi_{\mathrm{m}}$ and $\chi_{\mathrm{mFe}}$ in its surficial and organic matter-rich layer, which may be compared to the so-called magnetic enhancement often mentioned in soil magnetism studies $\underline{14}, \underline{18}$. Since the $\chi_{\mathrm{m}}$ values for the parent rock and the saprolitic unit exclude the presence of primary spinel, the ferrimagnetic phases are of secondary origin.

\subsubsection{Magnetic fabric}

In the fresh rock, saprolitic and transitional units (I), $P$ values are above 1.02 and the fabric shape is neutral to prolate $(T=0 ; \underline{F i g . ~} \mathrm{c}, \mathrm{d})$. These values, together with the directions of principal susceptibility axes (Fig. 2a) suggest a characteristic L-tectonite fabric [13]: $K_{1}$ grouping points toward a $\mathrm{N}-\mathrm{S}$ lineation while $K_{3}$ directions, dispersed in a roughly EW vertical plane, may correspond to a folded foliation. A heterogeneous inherited metamorphic fabric would account for the dispersion in $P$ and $T$ values, which show no clear vertical trend. 
The strong decrease in $P$ from the fresh parent rock to the saprolitic unit (Fig. 1c) is due to the pseudomorphic replacements of primary paramagnetic in the gneiss. The mimetic magnetic fabric [31] of the newly formed minerals preserves the fabric shape and orientation but the degree of alignment together with intrinsic anisotropy of the neoformed minerals are lower than for primary biotite.

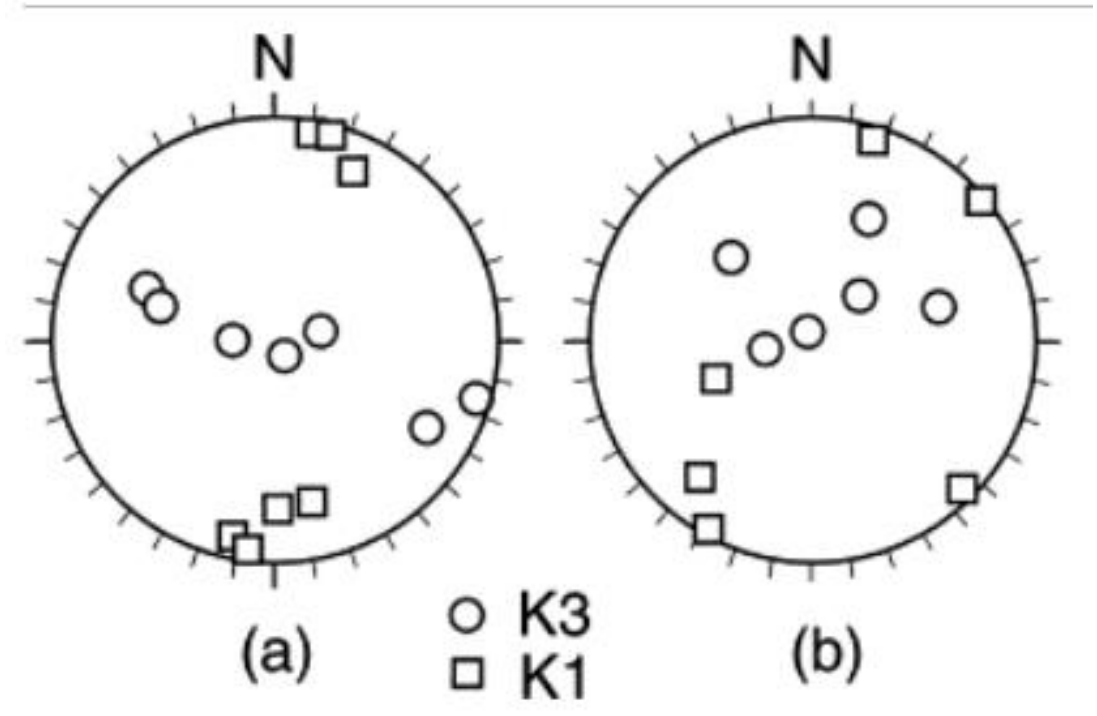

Fig. 2. Comparative equal-area plots of the mean directions of $K_{1}$ and $K_{3}$ principal susceptibility axes in geographic coordinates, calculated from three or four samples in each collected layer in the Goyoum profile 352: (a) units I and II'; (b) units II and III.

In contrast, the nodular unit show nearly isotropic fabric, with $P<1.008$, and a predominantly oblate shape $(T>0$; Fig. $1 \mathrm{c}-$ d). Since the magnetic mineralogy in this unit involves ferrimagnetic minerals, which can carry a stronger anisotropy than the paramagnetic and antiferromagnetic minerals present in the saprolitic unit (see also Table 1), the decrease of the $P$ values from the saprolite to the nodular unit is not due to mineralogical changes. Although changes in grain size may lower anisotropy degree [12], the strong decrease in $P$ probably indicates a randomization of the initial oriented structures, induced by ferralitic constant remobilization. Despite this low anisotropy a consistent horizontal planar fabric is observed with $K_{3}$ directions around vertical, and $K_{1}$ dispersed within the horizontal plane (Fig. 2b). This can be interpreted as a weak compaction fabric, more pronounced in the uppermost soil layer.

\subsection{Discussion}

The IMB method suggests that saprolitization proceeds on average with no major volumetric change in agreement with the magnetic fabric inherited from the parent rock without apparent deviation. The collapse of about $25 \%$ inferred from $\varepsilon_{\mathrm{Ti}}$ is not significant as it should have induce a compaction which is not consistent with the preservation of prolateness and anisotropy directions in the whole unit. The same argument can be made for the apparent dilation indicated by $\varepsilon_{\mathrm{Zr}}$ in the transition zone. AMS results are thus a strong indication that the bulk volume of the fresh parent rock was preserved in the saprolite and transition zone.

In the nodular unit as well as in the top soil unit the strong decrease in $P$ indicating randomized grain orientation may arise from three processes: particle transfers (translocation) or pedoplasmation (dilation/collapse of clay during wet/dry season); random orientations in 
magnetic coatings upon secondary kaolinite. The compaction magnetic fabric is compatible with the overall collapse indicated by IMB, although very large collapses and thus compaction inferred from $\varepsilon_{\mathrm{Th}}$ (up to $60 \%$ ) should have induced a strong preferred orientation of minerals. However, this apparent contradiction can be solved if one assume that most of the compaction occurred before the neoformation or reorientation of the magnetic grains due to the processes mentioned above.

Misleading values of strain, also illustrated by the large discrepancies observed between $\varepsilon_{i}$, may result from migration of solutes or translocation processes of the elements through the lateritic sequence, as it has been shown in the case of thorium in other similar toposequences in Cameroon [32]. Ti is clearly mobile, as shown by the unrealistic collapse in the saprolite and dilation at the top of nodular unit. It is difficult to evaluate, among $\mathrm{Th}$ and $\mathrm{Zr}$ which element is best suited for IMB in the present case. Our result do not disqualify Th, although collapse in the nodular unit may be too large. The iso-zirconium method may the more reliable apart from the unrealistic dilation found and the top of transition zone.

\section{The Ifrane profile (Morocco)}

The second example presented corresponds to the recent weathering of a quaternary basaltic flow $\underline{33}$, 34in the Middle-atlas (Morocco), located at $33^{\circ} 5^{\prime} \mathrm{N}$, near Ifrane, under cooler and dryer mountain climate. The two meters thick flow outcrops as rounded fresh basalt cores, about one meter diameter at the base (Fig. 3), surrounded by several coherent rims with increasing alteration from the inner ones to the outer ones. This weathering scheme is actually reproducible in the whole profile, and the main differences from cores to cores consist in a decrease in diameter upward as weathering increase. The upper part of the profile is a lithosoil, which occasionally fills voids between the rims and separate the cores from each other. These features enable to define a clear and progressive weathering gradient with distance to cores. Consequently, geochemical and AMS data will be represented as a function of the weathering facies: basalt cores, inner rims, outer rims and soil.

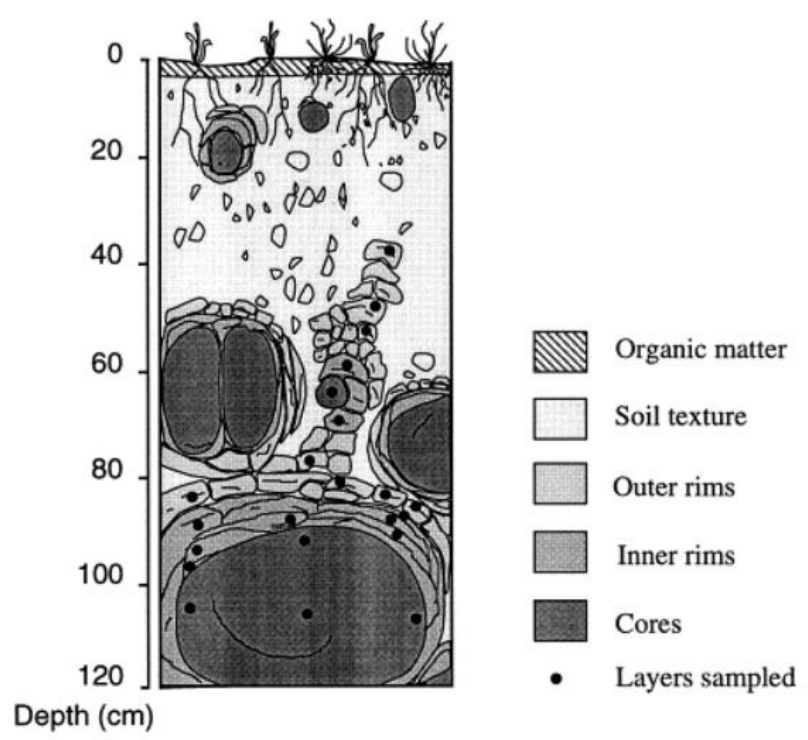

Fig. 3. Sketch of the Ifrane profile showing fresh basalt cores surrounded by grey (inner) and brown (outer) rims, together with brown-red soil. Black dots correspond to samples. 


\subsection{Petrological and mineralogical features}

Modal composition of the fresh alkaline basalt core is plagioclase $(57.6 \%)$, augite $(30 \%)$, olivine $(4.5 \%)$, opaque minerals $(6.5 \%)$ including ilmenite and titanomagnetite, accessory sphene and glass. Optical microscopy and SEM indicate that the opaque minerals appear as needles from 0.01 to $1 \mathrm{~mm}$ long in the glassy matrix and as granular inclusions in olivine phenocrysts. Structural formula inferred from microprobe analyses on separated crystals [34]and XRD patterns of magnetic extracts indicates that the needles are titanomaghemite [24]. Semi-quantitative determination of the whole mineralogical content, inferred from XRD patterns indicates that $25 \%$ of the inner rims consist in secondary minerals (mostly halloysite). In the outer rims, the clay content reaches $75 \%$ and consists in $90 \%$ halloysite and $10 \%$ vermiculite. Variations in the opaque mineral content from the basalt cores to the outer rims are of the order of the XRD detection limit (less than 5\%). Microprobe analyses of secondary products reveal some traces of iron, confirmed by FTIR spectrometry: the broad spectrum identifies some of the lattice vibration bands as belonging to goethite [34]. SEM observations, chemical analyses and porosity measurements on bulk material and separated minerals show that weathering proceeds by progressive dissolution and pseudomorphic replacements of the primary minerals.

\subsection{Volume changes}

$\varepsilon_{\mathrm{Ti}}$ and $\varepsilon_{\mathrm{Zr}}$ indicate a progressive dilation from the cores to the outer rims (Fig. 4) that reach $50 \%$ dilation in the more surficial outer rims. Their consistency within the probable error of analyses, together with the fact that the highest values of dilation correspond to the highest chemical content of the rock, suggests a common geochemical behavior of titanium and zirconium in that part of the profile. In the soil horizon, values of $100 \%$ dilation and even more, using both $\mathrm{Ti}$ and $\mathrm{Zr}$ as reference, are clearly unrealistic, and cannot only be due to low chemical content, with regard to the discrepancies observed between $\varepsilon_{\mathrm{Zr}}$ and $\varepsilon_{\mathrm{Ti}}$, as well as the scattered values of $\varepsilon_{\mathrm{Zr}}$ or $\varepsilon_{\mathrm{Ti}}$. 


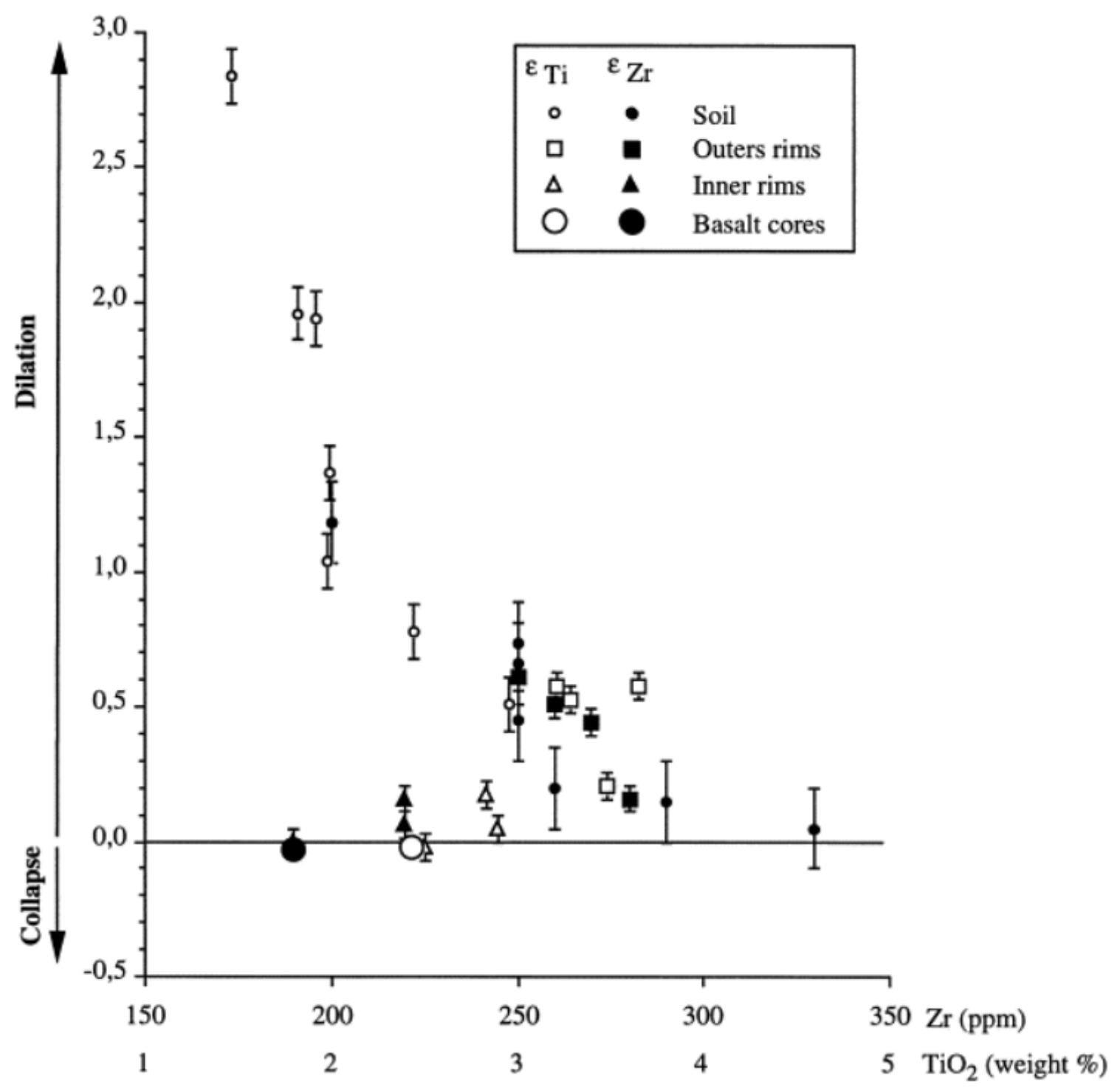

Fig. 4. Strains $\varepsilon_{i}$ for the different units of the Ifrane profile, calculated using titanium and zirconium as index elements, plotted against the contents of $\mathrm{TiO}_{2}(\mathrm{wt} \%)$ and $\mathrm{Zr}(\mathrm{ppm})$ of the whole rock. Solid and open symbols: $\mathrm{Zr}$ and $\mathrm{Ti}$ taken as index element respectively. Large dots: basalt cores; triangles: inner rims; squares: outer rims; small dots: soil.

\subsection{AMS results}

\subsubsection{Magnetic mineralogy}

High mean susceptibility values $\left(\chi_{\mathrm{m}}>10^{-6} \mathrm{~m}^{3} / \mathrm{kg}\right)$, together with high field susceptibility measurements $[24]$ demonstrate the strongly predominant contribution of ferrimagnetic phases in the whole profile, with a slight decrease between the fresh cores and the rims (Fig. 5). In all cases, low-field susceptibility versus temperature curves (Fig. 6) exhibit upon heating a decrease around $300^{\circ} \mathrm{C}$ followed by an irreversible enhancement of susceptibility around $400^{\circ} \mathrm{C}$ with Curie temperatures of about $570^{\circ} \mathrm{C}$. Such behavior is typical of the irreversible transformation of titanomaghemite into ilmenohematite and titanium-poor magnetite intergrowths of higher susceptibility $\underline{24}, \underline{35}$. The similarity between low-field susceptibility curves from the cores to the outer rims suggests that titanomaghemite was already present 
before weathering (due to deuteritic alteration) and remain practically unchanged throughout weathering.
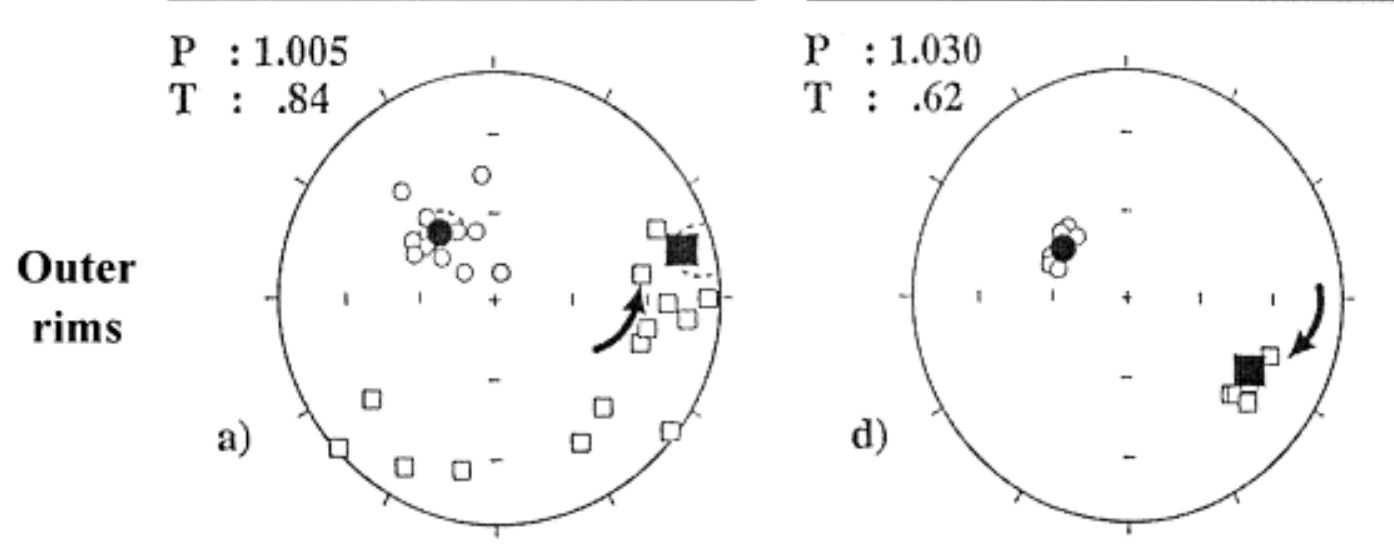

$$
\chi_{\mathrm{m}(\text { ave })}=2031.2 \pm 135.8
$$

$$
\left.\chi_{\mathrm{m}} \text { (ave }\right)=5243.8 \pm 1043.5
$$
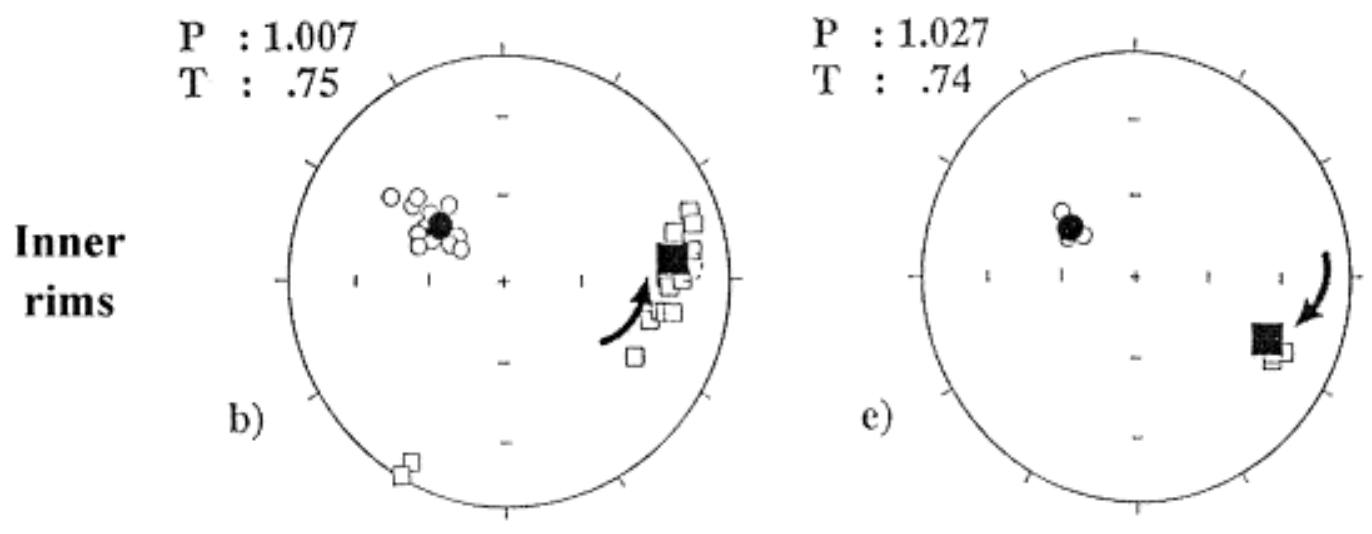

$$
\chi_{\mathrm{m}(\text { ave })}=1888.0 \pm 83.9
$$

$$
\chi_{\mathrm{m}}(\text { ave })=3399.5 \pm 978.9
$$

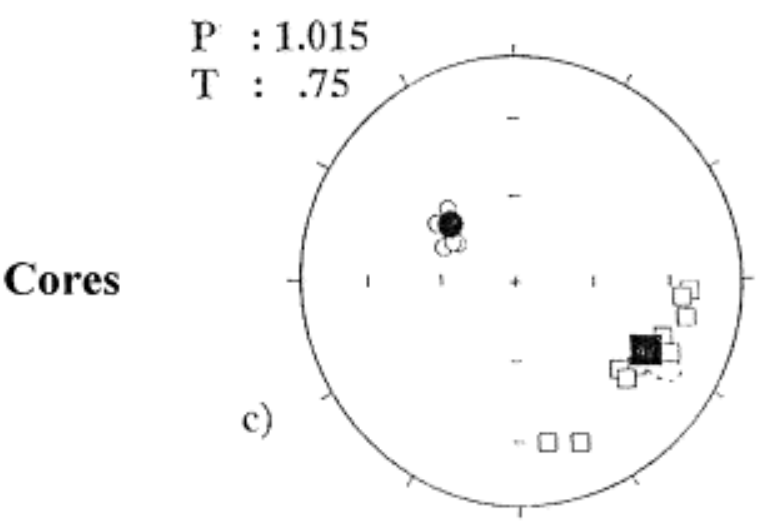

$$
\chi_{\mathrm{m}(\text { ave })}=2731.2 \pm 396.9
$$

\section{Direction of principal} susceptibility axes

$$
\square \mathrm{K}_{1} \circ \mathrm{K}_{3}
$$

Tensorial mean directions for $E_{12}<30$ and $E_{23}<30$

$$
\mathrm{K}_{1} \bullet \mathrm{K}_{3}
$$

Fig. 5. Mean tensorial values of $\chi_{m}, P, T$ and comparative equal-area plots of the $K_{1}$ and $K_{3}$ principal susceptibility axes in geographic coordinates for the Ifrane profile. Unheated samples: (a) outer rims; (b) inner rims; (c) basalt cores. Open and closed symbols correspond to sample and mean directions, respectively. Samples heated 3 hours to $350^{\circ} \mathrm{C}$ : (d) outer rims; (e) inner rims. $\chi_{\mathrm{m}}$ (ave) in $10^{-9} \mathrm{~m}^{3} / \mathrm{kg}$. 


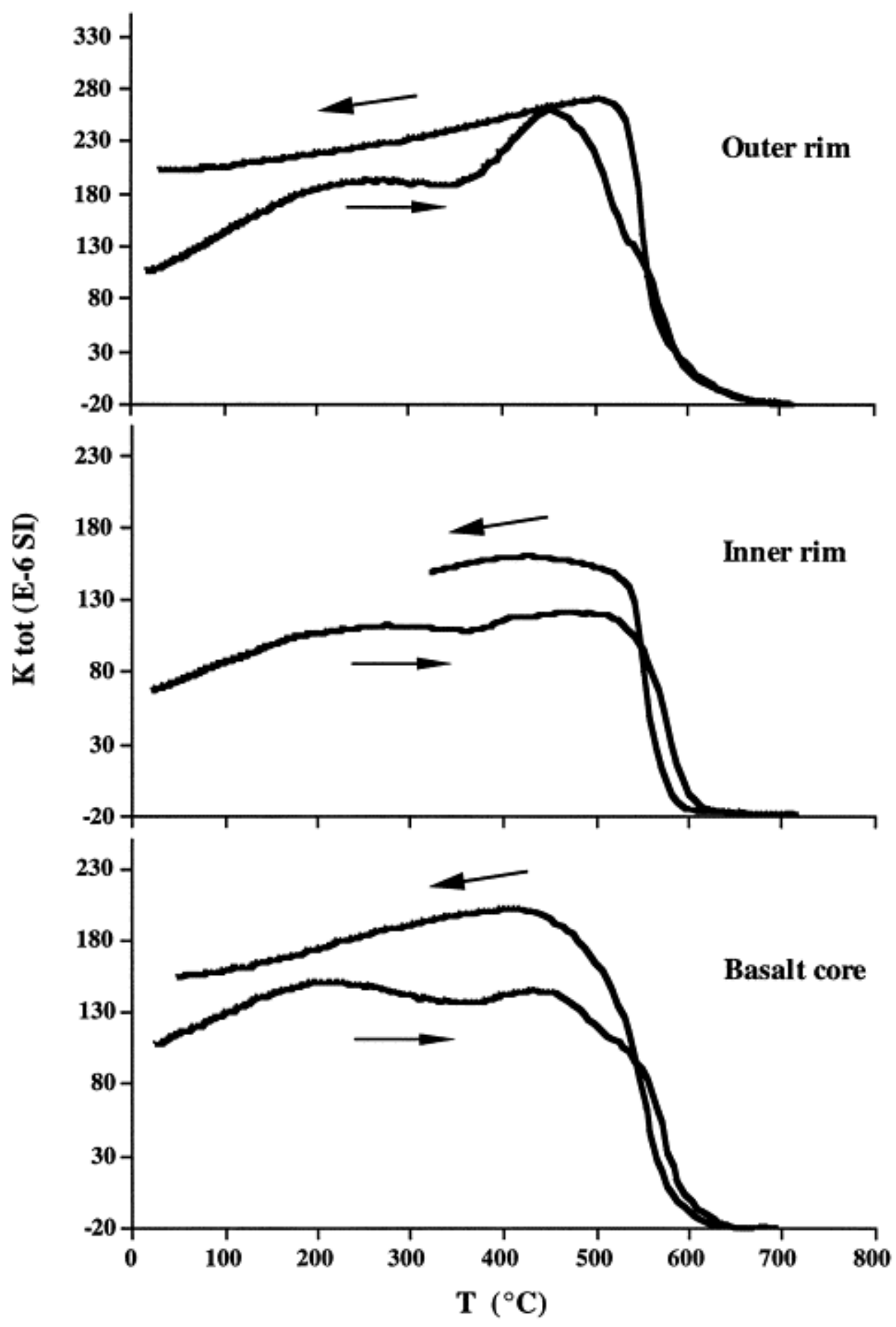

Fig. 6. Low-field magnetic susceptibility versus temperature (CS2 apparatus) for the Ifrane profile. From the cores to the outer rims, samples exhibit similar behavior imparted to a mixture of titanomaghemite grains.

\subsubsection{Magnetic fabric}

In the basalt cores (Fig. 5c), the AMS parameters, $P=1.015$, oblate shape and weakly dipping foliation, are characteristic of an imbricated magmatic flow fabric $\underline{13}, \underline{36}$, with a northwestward flow consistent with the paleslope morphology [24]. The decrease in $P$ to 
1.007 in the inner rims and to 1.005 in the outer rims (Fig. $5 \mathrm{~b}$ and a), without any major influence on the initial oblateness of the AMS ellipsoid ( $T=0.75$ and $T=0.84$ in the inner and outer rims respectively), is associated with an increased scattering of anisotropy directions. The mean foliation (perpendicular to $K_{3}$ ) is unchanged while the lineation (mean $K_{1}$ ) rotates toward the EW direction. Very low anisotropy ratio can account for the scattering but not for the deviation. A thermal enhancement of the magnetic fabric $12, \underline{37}$ was attempted by heating the samples for three hours at $350^{\circ} \mathrm{C}$. Indeed, $P$ values increase drastically, above initial values for fresh basalt, and the scattering of directions together with the lineation deviation disappear. After heating the fabric of fresh basalts and the weathered rims are indistinguishable in directions, shape and intensity. So, we assume that the magnetic fabric of the unheated weathered samples corresponds to a mixture of the primary flow fabric (suggested by the preservation of $K_{3}$ direction in the whole profile) and a superimposed weathering-induced fabric, which is reversible under heating. This latter fabric is probably due to internal stresses and crystal defects in the titanomaghemite structure, removed by diffusion during thermal treatment. This behavior should be then related to coercivity changes and a progressive oxidation of the grains as weathering increase. The shift of the mean tensorial $K_{1}$ direction toward an E-W lineation as weathering increases also suggests that the acquisition of a chemical remanence (CRM) [28]in the Earth magnetic field direction, may induce a magnetic lineation perpendicular to CRM direction $\underline{12}, \underline{38}$. The loss of anisotropy between the fresh basalt core and the rims, may also be explained by the partial dissolution of titanomaghemite needles $\underline{24}, \underline{34}$, reducing the shape aspect ratio of the ferrimagnetic grains.

\subsection{Discussion}

Thermal enhancement of AMS have shown that the change of initial magnetic fabric from fresh basalt to the weathered rims is not due to a strain induced physical realignment of grains but to an effect of CRM acquisition and internal grain stress or partial dissolution. In fact, weathering induces no detectable changes in the preferred orientation of the primary titanomaghemite grains. Due to the weak initial magmatic fabric, only a weak strain (e.g. 10\% or less) is necessary to overprint this fabric [39]. Therefore, vertical constriction of more than $50 \%$ in the outer rims, corresponding to the dilation calculated by IMB method (Fig. 4) is clearly unrealistic and AMS results plead for an isovolumetric weathering in this profile. This implies absolute losses of both $\mathrm{Zr}$ and $\mathrm{Ti}$ from the outer rims, in such a way that consistency between $\varepsilon \mathrm{Zr}$ or $\varepsilon_{\mathrm{Ti}}$ values is preserved. The petrological study at different scales [34]do not revealed any zirconium bearing minerals that are supposed to be present as a basis for assuming non-mobility of this element [26]. It also demonstrated that among the three possible relevant host phases for Zr, which are glassy matrix [4], feldspar and dark minerals such as ilmenite [40], the first two are highly susceptible to alteration. For ilmenite, the magnetic study [24]shows a dissolution of fine-grained titanomaghemite, and ilmenite probably behaves similarly [41]. This provides possible explanations for the mobility of these elements.

Moreover, the operation of short term transfers via connected porosity, which confine these elements to the layers from which they originate, and hence, make strain calculations valid, have yet to be demonstrated. The fact that chemical analyses of the ground waters do not reveal any detectable amounts of both elements in solution (detection limit at $2 \mathrm{ppm}$ ) is not a sufficient basis for proving their immobility. The leaching rate under semi-arid mountain conditions may be slow enough that ppb concentrations would be sufficient to translocate significant amounts of $\mathrm{Ti}$ and $\mathrm{Zr}$ in solution. For instance, assuming on a paleomagnetic basis [24] that the age of the basalt flow is less than $0.78 \mathrm{Ma}$, the complete dissolution of the initial 
zirconium content of the fresh basalt (174 ppm) over this period of time gives a dissolution rate of $20 \mathrm{ppb} / \mathrm{y}$ in solution, well below the detection limit used in this investigation.

\section{Conclusion}

These two examples show that magnetic fabric is a very promising new approach to understand weathering induced structural changes.

In the case of the equatorial mature lateritic profile developed on a spinel-free parent rock, magnetic mineralogy is dominated by neoformations and AMS mainly reflects structural changes, from saprolite where the magnetic fabric is mainly due to inherited structure, to iron crust where the initial fabric is erased, leading to isotropy and a weak compaction fabric.

When the primary magnetic mineralogy is dominated by spinels, which is the case of the recent weathering of a basalt flow, AMS is dominated by coercivity changes and/or grainshape behavior due to further oxidation and dissolution of the inherited titanomaghemite grains. However, this superimposed weathering fabric did not erase the primary fabric of the basalt flow, and hence, the former can indirectly give major clues on the structural evolution of the saprolite.

In both cases, the weathering fabric in the saprolite leads to a loss of anisotropy degree but a preservation of the primary metamorphic or magmatic fabric, indicating no deviatoric strain and thus isovolumetric weathering.

This comparison of strain estimated by the IMB and AMS techniques shows that in both case studies, the large values of strain often inferred by the IMB method are unrealistic. The assumption of the immobility of the elements taken as a reference - either titanium, zirconium or thorium - is actually not fulfilled, at least in the two examples studied. Moreover, while the validity of strain calculations is usually improved by the consistency of results from several reference elements, the AMS technique demonstrates, on the basis of results obtained from the profile from Morocco, that such a cross-check was unable to detect the geochemical mobility of Ti and Zr, which make the validity of the IMB methods not selftestable.

\section{Acknowledgements}

We are greatly indebted to A. Dekayir and J.P. Muller for providing samples and various unpublished data. Field work, funded by ORSTOM and PEGI-INSU, have benefited from the help of J.J. Braun and B. Hamelin in Cameroon, S. Kamel and H. Ouazzani in Morocco. J.J. Motte is thanked for preparing the illustrations. [FA] 
R.W. Arnold, I. Szabolcs, V.O. Targulian (Eds.), IIASA-ISSS-UNEP task force on the role of soils in global change, Laxenburg, Austria, International Institution of Applied System, 1990, $110 \mathrm{pp}$.

J.-J. Cramer, H.W. Nesbitt Mass balance relations and traces-elements mobility during continental weathering of various igneous rocks Sci. Géol. Mém. Strasbourg, 73 (1983), pp. 63-73

H.W. Nesbitt, R.E. Wilson Recent chemical weathering of basalts Am. J. Sci., 292 (1992), pp. 740-777

H.W. Nesbitt Mobility and fractionation of rare earth elements during weathering of a granodiorite Nature, 279 (1979), pp. 206-210

B. Boulangé, Les formations bauxitiques latéritiques de Côte-d'Ivoire. Les faciès, leur transformation, leur distribution et l'évolution du modelé, Trav. Doc. ORSTOM (Off. Rech. Sci. Tech. Outre-Mer), Paris, 175, 1984, 272 pp.

J.-J. Braun, M. Pagel, A. Herbillon, C. Rosin Mobilization and redistribution of REE and thorium in a syenitic lateritic profile: a mass balance study Geochim. Cosmochim. Acta, 57 (1993), pp. 4419-4434 G.H. Brimhall, W.E. Dietrich Constitutive mass-balance relations between chemical composition, volume, density, porosity and strain in metasomatic hydrochemical systems: results on weathering and pedogenesis Geochim. Cosmochim. Acta, 51 (1986), pp. 567-587

F. Colin, P. Veillard, J.-P. Ambrosi Quantitative approach to physical and chemical gold mobility in equatorial rainforest lateritic environment Earth. Planet. Sci. Lett., 114 (1993), pp. 269-285

D. Nahon, E. Merino Pseudomorphic replacement in tropical weathering: evidence, geochemical consequences, and kinetic-rheological origin Am. J. Sci., 297 (1997), pp. 393-417

D.B. Nahon, Introduction to the Petrology of Soils and Chemical Weathering, Wiley, New York, 1991, $313 \mathrm{pp}$.

G. Millot, M. Bonifas Transformations isovolumétriques dans les phénomènes de latéritisation et de bauxitisation Bull. Serv. Carte Géol. Alsace Lorraine, 8 (1955), pp. 3-10

P. Rochette, M. Jackson, C. Aubourg Rock magnetism and the interpretation of anisotropy of magnetic susceptibility Rev. Geophys., 30 (3) (1992), pp. 209-226

D.H. Tarling, F. Hrouda, The Magnetic Anisotropy of Rocks, Chapman and Hall, London, 1993, 217 pp.

E. Le Borgne Susceptibilité magnétique anormale du sol superficiel Ann. Geophys., 11 (1955), pp. 399-419

Ö. Özdemir, S. Banerjee A preliminary study of soil samples from west-central Minnesota Earth Planet. Sci. Lett., 59 (1982), pp. 393-403

M. Resende, J.M.D. Coey, J. Allan The magnetic soils of Brazil Earth Planet. Sci. Lett., 78 (1986), pp. 322-326

J.J. Hus, W. Stiers The magnetic properties of an ironcrust in SE Belgium and synthetic Mnsubstituted goethites Phys. Earth Planet. Inter., 46 (1987), pp. 247-258

R. Thompson, F. Oldfield, Environmental Magnetism, Allan and Unwin, London, 1986, 227 pp.

P.W. Schmidt, B.J.J. Embleton Palaeomagnetic result from sediments of the Perth basin, Western Australia and their bearing on the timing of regional lateritization Palaeogeol. Palaeoclimatol. Palaeoecol., 19 (1976), pp. 257-273

P.W. Schmidt, P.K. Ramam, V. Prasad Magnetic ages of some Indian laterites Palaeogeol.

Palaeoclimatol. Palaeoecol., 44 (1983), pp. 185-202

A.U. Gehring, F. Heller, P. Keller Magnetic evidence for the origin of lateritic duricrust in Southern Mali (Western Africa)Palaeogeol. Palaeoclimatol. Palaeoecol., 95 (1992), pp. 33-40 $\checkmark$. Jelinek Statistical processing of anisotropy of magnetic susceptibility measured on groups of specimens Stud. Geophys. Geodet., 22 (1978), pp. 50-62 
J.-P. Muller, Analyse pétrologique d'une formation latéritique meuble du Cameroun, unpublished thesis, Univ. Paris 7, 1987, 188 pp.

P.-E. Mathé, Application du paléomagnétisme et du magnétisme des roches aux processus d'altération supergène, unpublished Ph.D. thesis, Univ. Aix-Marseille III, 1996, 212 pp.

G.H. Brimhall, O.A. Chadwick, C.J. Lewis, W. Compston, I.S. Willams, K.J. Danti, W.E. Dietrich, M.E. Power, D. Hendricks, J. Bratt Deformational mass transport and invasive process in soil evolution Science, 255 (1992), pp. 695-702

A. Beauvais, F. Colin Formation and transformation processes of iron duricrust systems in tropical humid environment Chem. Geol., 106 (1993), pp. 77-101

R.J. Pollard, Q.A. Pankhrust, P. Zientek Magnetism in aluminous goethite Phys. Chem. Miner., 18 (1991), pp. 259-264

M.J. Dekkers, Some rockmagnetic parameters for natural goethite, pyrrhotite and finegrained hematite, Geol. Ultraiectina 51 (1988) 231 pp.

P. Rochette, G. Fillion Field and temperature behavior of remanence in synthetic goethite: paleomagnetic implications Geophys. Res. Lett., 16 (1989), pp. 851-854

M. Boudeulle, J.-P. Muller Structural characteristics of hematite and goethite and their relationships with kaolinite in a laterite from Cameroon: A TEM study Bull. Minéral., 111 (1988), pp. 149-166

R. Kligfield, W.W. Lowrie, O.A. Pfiffner Magnetic properties of deformed oolitic limestones from the Swiss Alps: the correlation of magnetic anisotropy and strain Eclogae Geol. Helv., 75 (1981), pp. 127-157

J.-J. Braun, M. Pagel, A. Herbillon, C. Rosin Mobilization and redistribution of REEs and thorium in a syenitic lateritic profile Geochim. Cosmochim. Acta, 57 (1993), pp. 4419-4434 $\mathrm{H}$. Bellon, Séries magmatiques néogènes et quaternaires du pourtour de la Méditerranée occidentale, comparée dans leur cadre géochronométrique; implications géodynamiques, unpublished Ph.D thesis, Univ. Orsay, 1976, 367 pp.

A. Dekayir, Étude de l'altération supergène d'un basalte altéré alcalin quaternaire du MoyenAtlas (Maroc), unpublished Ph.D. thesis, Univ. Aix-Marseille III, 1994, 181 pp.

Ö. Özdemir Inversion of titanomaghemites Phys. Earth Planet. Inter., 46 (1987), pp. 184-196

P. Rochette, C. Aubourg, M. Perrin, Is this magnetic fabric normal? A review and case studies in volcanic formations, Tectonophysics in press.

A. Perarnau, D.H. Tarling Thermal enhancement of magnetic fabric in Cretaceous sandstone J. Geol. Soc. London, 142 (1985), pp. 1029-1034

L. Stokking, L. Tauxe Properties of chemical remanence in synthetic hematite: testing theoretical predictions J. Geophys. Res., 95 (1990), pp. 12639-12652

$\mathrm{K}$. Benn Overprinting of magnetic fabrics in granites by small strains: numerical modelling Tectonophysics, 233 (1994), pp. 153-162

W.D. Ehmann, L.L. Chyi, A.N. Garg, M.Z. Ali, The distribution of zirconium and hafnium in terrestrial rocks, meteorites and the Moon, in: Origin and Distribution of the Elements, Second Symp. Proc., Phys. Chem. Earth II (1977) 247-259.

A. Edou-Minko, F. Colin, J.-J. Trescases Altérabilité des minéraux titanés (ilménite et rutile) et mobilité du titane dans les profils d'altération du secteur d'Ovala (Gabon)

J. Afr. Earth Sci., 21 (1995), pp. 313-318 